\title{
Síntese de zeólita do tipo faujasita: comparação entre caulim beneficiado e caulim flint
}

\author{
(Sinthesis of faujasite-type zeolite: comparison between \\ processed and flint kaolin)
}

\author{
C. A. F. Rocha Junior ${ }^{1, *}$, R. S. Angélica ${ }^{1}$, R. F. Neves ${ }^{1,2}$ \\ ${ }^{1}$ Instituto de Geociências - IG, ${ }^{2}$ Faculdade de Engenharia Química - FEQ, Universidade Federal do Pará - \\ UFPA, R. Augusto Corrêa 1, Guamá, PA 66075-110 \\ *augustorocha2@gmail.com
}

\begin{abstract}
Resumo
O trabalho tem como objetivo a síntese de zeólita faujasita a partir de três tipos de caulim da região amazônica: dois caulins provenientes do processo de beneficiamento de caulim para cobertura de papel e caulim duro, um caulim não processado originado da lavra do caulim. Produtos da zeolitização dos caulins mostraram a formação de zeólita do tipo faujasita. O caulim duro mostrou baixo potencial de zeolitização na relação de $\mathrm{Si} / \mathrm{Al}$ igual a 2 em comparação com os caulins beneficiados, possivelmente relacionado a presença de compostos de ferro no caulim não processado. Após a remoção do ferro, novos resultados mostraram uma completa mudança quanto a formação de zeólita faujasita, passando esta para a fase mineralógica dominante.
\end{abstract}

Palavras-chave: faujasita, sintese, caulim, ferro.

\begin{abstract}
The main purpose of this work is the synthesis of faujasite zeolite using three different kinds of kaolin from the Amazon region, Brazil: two kaolin from the beneficiation process for paper coating and hard or flint kaolin, a non-processed kaoling from the mining site. Analysis of the reaction products of kaolin showed the formation of faujasite zeolite. Flint kaolin showed a lower potential with respect to zeolitization ratio Si/Al equal to 2, compared to processed kaolins, probably related to the iron present in the structure. New results show a complete change in the formation of faujasite, which turns to be the main mineralogical phase after iron removal.
\end{abstract}

Keywords: faujasite, synthesis, kaolin, iron.

\section{INTRODUÇÃO}

O Brasil é um país que apresenta enorme potencial geológico, apresentando uma extensa área territorial, propícia à exploração mineral. Dentro deste cenário, a região amazônica apresenta-se com ampla potencialidade para a exploração de recursos minerais tais como, o ferro, manganês, cobre, ouro, estanho, bauxita, caulim entre outros. As reservas brasileiras relacionadas ao caulim estão avaliadas em $28 \%$ da estimativa mundial, sendo que dentro do território nacional estas reservas concentram-se em sua quase totalidade (93\%) nos depósitos sedimentares dos três maiores distritos cauliníferos do país: Rio Capim no estado do Pará, Jari no Estado do Amapá e no município de Manaus, no Estado do Amazonas [1]. No Estado do Pará estes depósitos são propriedade de três empresas exploradoras de caulim, a Imerys Rio Capim Caulim S/A - IRCC, Pará Pigmentos S/A - PPSA e a Companhia Brasileira de Equipamento - CBE. As duas primeiras utilizam o caulim na indústria do papel, para revestimento e cobertura e a última, na indústria de cimento como pozolana. No âmbito econômico brasileiro, estas empresas apresentam uma clara importância. Porém, o processo de beneficiamento do caulim nestas empresas traz um grande impacto ambiental, gerando grandes quantidades de resíduos durante a transformação do caulim bruto, para um produto comercial. Neste processamento três resíduos são gerados: um rico em quartzo, outro constituído principalmente de caulim com granulometria grosseira e o terceiro formado por caulim com alto teor de ferro.

No caso do caulim ferruginoso existe um aproveitamento de $15 \%$ para ser usado com o caulim industrialmente aproveitável, quando o mesmo apresenta um teor baixo em ferro, ficando o restante disposto na mina após a exploração. Os outros dois resíduos são depositados em extensas lagoas de rejeito, que necessitam de grandes áreas desmatadas para sua construção. Estas lagoas trazem enormes perdas ao ecossistema regional, apesar de serem implantados projetos de reflorestamento em parte destas áreas, mas como se saber, uma completa recuperação da área afetada jamais será alcançada.

Para minimizar os impactos ambientais causados pelos resíduos da industrial do caulim, vários trabalhos foram 
desenvolvidos a fim de aproveitar estes materiais em diversos processos tecnológicos como, na produção de zeólitas [28], material adsorvente [9], cerâmica e refratários [10, 11] e cimento $[12,13]$.

A semelhança na composição química destes resíduos cauliníticos, com o material vulcânico precursor das zeólitas naturais foi a principal razão do desenvolvimento de experimentos envolvendo a síntese de zeólitas a partir desta matéria-prima. A obtenção de inúmeros tipos de zeólitas a partir de caulim calcinado como: zeólita X, Y, A, P, S, L, K-F, D entre outras, foi reportada [14]. As duas primeiras apresentam destaque quanto à utilização em processos de craqueamento catalítico, bem como adsorção.

As zeólitas $\mathrm{XeY}$ apresentam estruturas cristalinas idênticas (isoestruturais), porém mostra características diferentes, tanto na sua composição química quanto nas suas propriedades físicas e químicas. Estas diferenças residem principalmente na relação $\mathrm{Si} / \mathrm{Al}$, na qual esta varia de 1 a 1,5 para a zeólita $\mathrm{X}$ e 1,5 a 3 para Y. Esta maior quantidade de alumínio na estrutura da zeólita $\mathrm{X}$, confere uma maior capacidade de troca catiônica, já a maior quantidade de silício na zeólita Y, reflete uma maior estabilidade térmica e hidrotérmica $[14,15]$. A igualdade quanto a estrutura das zeólitas $\mathrm{X}$ e Y acarreta uma dificuldade na distinção desta através de uma simples análise de difração de raios $\mathrm{X}$, no entanto, outras técnicas como químicas e físicas podem auxiliar a exemplo, análise térmica, química, capacidade de adsorção, superfície específica, troca iônica, condutividade iônica, infravermelho entre outras [16].

Este trabalho objetiva a utilização de três tipos de caulim para a síntese de zeólita do tipo faujasita (X e Y). Dois destes, o caulim de enchimento (CE) e tube press (CTP), produto e semi-produto do beneficiamento na indústria do papel e um terceiro, um resíduo caulinítico denominado caulim flint ou duro (CD). A escolha dos caulins beneficiados e residual tem como objetivo a comparação entre estes, bem como seus produtos zeolíticos, a fim de avaliar o potencial do resíduo industrial, frente a matérias primas já tratadas, pois a utilização de material de partida de baixo custo oferece vantagens econômicas sobre material beneficiado.

\section{MATERIAIS E MÉTODOS}

Difração de raios $X(D R X)$ : Para a análise mineralógica houve uma prévia pulverização de cada uma das amostras em um gral de ágata, sendo posteriormente transferida para portas-amostra de aço inox, utilizados como suporte na análise de DRX. As análises foram realizadas em difratômetro de raios X X'PERT PRO MPD (PW 3040/60) da PANalytical, com goniômetro PW3050/60 (teta-teta), tubo de raios $\mathrm{X}$ de $\mathrm{Cu}\left(\mathrm{k} \alpha_{1}=1,540598 \AA\right)$. A faixa angular de varredura foi entre $4^{\circ} \mathrm{e} 75^{\circ}(2 \theta)$, voltagem $40 \mathrm{kV}$ e corrente $30 \mathrm{~mA}$; tamanho do passo de $0,02^{\circ}(2 \theta)$, e tempo/passo de $20 \mathrm{~s}$, fenda divergente de $1 / 4^{\circ}$, máscara de $10 \mathrm{~mm}$ e rotação com 1 rps.

Espectrometria de fluorescência de raios X (FRX): As composições químicas de cada caulim foram obtidas por espectrometria de fluorescência de raios $\mathrm{X}$ em um espectrômetro Axios Minerals da PANalytical. Para cada uma das análises foi preprado um disco de vidro com aproximadamente $1 \mathrm{~g}$ de cada amostra e $8 \mathrm{~g}$ do fundente tetraborato de lítio.

Microscopia eletrônica de varredura (MEV): As análises de foram realizadas em um microscópio Zeiss LEO 1430. A metalização com Ptdas amostras foi feita com equipamento Emitech K550, a uma pressão de $2.10^{-1}$ mbar e corrente de $25 \mathrm{~mA}$ durante $2,5 \mathrm{~min}$. As imagens foram geradas por elétrons secundários com voltagens de $20 \mathrm{kV}$.

Análise térmica diferencial e gravimétrica (ATD e $T G$ ): O equipamento PL Thermal Sciences, com analisador térmico simultâneo STA 1000/1500 da Stanton Redcroft Ltda, foi utilizado. As amostras foram submetidas a uma varredura da temperatura ambiente até $1100{ }^{\circ} \mathrm{C}$, com uma taxa de aquecimento de $20^{\circ} \mathrm{C} \cdot \mathrm{min}^{-1} \mathrm{sob}$ atmosfera estática.

Caulim: Os caulins são provenientes da região amazônica, a partir do processo de beneficiamento do caulim para a indústria do papel. O caulim duro ou flint (CD) é um rejeito, tube press (CTP) um subproduto do processo e o de enchimento (CE) um dos produtos finais.

Análise do teor de ferro no caulim duro: Para a análise de ferro total, tanto in natura quanto calcinado a 600 e $700{ }^{\circ} \mathrm{C}$, utilizou-se a metodologia de abertura para solos e rochas, que consistiu na pesagem de $0,2 \mathrm{~g}$ de cada amostra em um cadinho de teflon, adicionando-se $5 \mathrm{~mL}$ de $\mathrm{HCl}$ concentrado. Posteriormente, cada cadinho foi aquecido em um banho de areia até a secura total, e após resfriamento foi adicionado $7 \mathrm{~mL}$ da mistura $\mathrm{HF}: \mathrm{HClO}_{4}(10+1)$, e novamente aquecido até a secura total, sendo repetido este processo por mais duas vezes, com $5 \mathrm{~mL}$ e $3 \mathrm{~mL}$ da mistura $\mathrm{HF}: \mathrm{HClO}_{4}(10+1)$. Por fim, após novo resfriamento do cadinho foi adicionado $5 \mathrm{~L}$ de $\mathrm{HCl}(1+1)$ para dissolver qualquer material, transferindose todo este conteúdo para um balão de $100 \mathrm{~mL}$, para posterior análise.

Tratamento do caulim duro (extração de ferro): Foi realizado segundo a metodologia de Mehra e Jackson [17], aplicada tanto em amostras in natura, quanto calcinada a 600 ${ }^{\circ} \mathrm{C}$ e $700{ }^{\circ} \mathrm{C}$, a fim de avaliar a melhor forma de extração. As extrações de ferro de cada caulim foram realizadas em triplicata, cada ensaio constituído de $1 \mathrm{~g}$ de amostra. O procedimento de extração foi repetido 4 vezes em cada amostra, realizado em um tempo de 15 min cada processo. O líquido sobrenadante foi transferido para um frasco de polietileno, para posterior análise colorimétrica do ferro extraído. Os resultados obtidos para as triplicatas de cada caulim foram comparadas estatisticamente, através do teste de Tukey, para avaliar possíveis variações em cada extração. Em seguida, tirou-se uma média para cada triplicata, e comparou-se os resultados a fim de obter a melhor forma de extração do ferro. 
Análise colorimétrica do ferro em solução: A análise do teor de ferro nas soluções estoque do caulim duro in natura, calcinado a 600 e $700{ }^{\circ} \mathrm{C}$ obtidos a partir da abertura ácida e do tratamento pelo metodo de Mehra e Jackson [17] foram feitas em um espectrofotometro de UV-Visível Varian Cary 50 Probe utilizando-se um comprimento de onda de $510 \mathrm{~nm}$. Em cada análise, tomou-se uma aliquota de cada solução estoque e transferiu-se para um balão de $100 \mathrm{~mL}$, posteriormente $5 \mathrm{~mL}$ de solução de cloridrato de hidroxilamina $(10 \%)$ foi adicionada ao balão, deixando-o repousar por $10 \mathrm{~min}$. Após este periodo $10 \mathrm{~mL}$ de solução de citrado de sódio $(10 \%)$ e $10 \mathrm{~mL}$ de ortofenantrolina $(0,1 \%)$ foram adicionadas ao balão, completando-se o volume com água deionizada. Após homogenização e periodo de repouso de $1 \mathrm{~h}$, para reação dos constituintes da solução, foi feita a leitura do teor de ferro.

Processo de sintese zeolítica: Para o estudo de síntese da zeólita do tipo faujasita utilizou-se como fonte de silício e alumínio três diferentes tipos de caulim: duro ou flint (CD), tube press $(\mathrm{CTP})$ e enchimento $(\mathrm{CE})$ calcinados a $600{ }^{\circ} \mathrm{C} \mathrm{e}$ $700{ }^{\circ} \mathrm{C}$. Estes foram escolhidos a fim de avaliar o potencial de zeolitização de uma matéria prima in natura (CD) em relação a uma beneficiada (CE e CTP). Adicionalmente, foram utilizados água destilada, metassilicato de sódio sólido $\left(\mathrm{Na}_{2} \mathrm{SiO}_{3}\right)$ e hidróxido de sódio sólido $(\mathrm{NaOH})$. O metassilicato foi empregado para modificar a relação $\mathrm{Si} / \mathrm{Al}$ e em conjunto com o hidróxido fornecer sódio para formação da zeólita. O sistema reacional consistiu na mistura de cada tipo de caulim com metassilicato de sódio, hidróxido de sódio e água em reatores de aço inox com revestimento de teflon, submetido à temperatura de $110^{\circ} \mathrm{C}$ por um período de $13 \mathrm{~h}$, em uma estufa com atmosfera estática. A quantidade de cada componente da mistura foi calculada estequiometricamente para estudar as relações de $\mathrm{Si} / \mathrm{Al}$ de 2, 4 e 6 sendo mantido o meio reacional com relações fixas de $\mathrm{H}_{2} \mathrm{O} / \mathrm{Na}_{2} \mathrm{O}$ e $\mathrm{Na}_{2} \mathrm{O}$ / $\mathrm{SiO}_{2}$ com valores de 40 e 1,9, respectivamente. Estas relações fixas [18] são valores promissores para a formação da zeólita faujasita. Após o período de síntese, os reatores foram retirados da estufa e resfriados. Todos os materiais reacionais foram filtrados e lavados com água deslilada até $\mathrm{pH}$ igual 7. O resíduo sólido de cada filtração foi seco em estufa a $110{ }^{\circ} \mathrm{C}$ por $24 \mathrm{~h}$, e acondicionado em frasco de polietileno para posterior análise.

\section{RESULTADOS E DISCUSSÃO}

\section{Caulim}

Análise de difração de raios $X$ : Observam-se 4 fases mineralógicas: o argilomineral caulinita $(\mathrm{K})$, como fase principal, caracterizado pela presença dos seus principais picos em 7,15 (001) e 3,56 $\AA$ (002), assim como minerais acessórios com picos de baixa intensidade como quartzo $(\mathrm{Q})$, anatásio (A) e hematita $(\mathrm{H})$, este último somente observado para o caulim duro. Estes resultados também foram apresentados no estudo de caulins da mesma região amazônica [3, 19]. Com relação ao grau de ordem ou

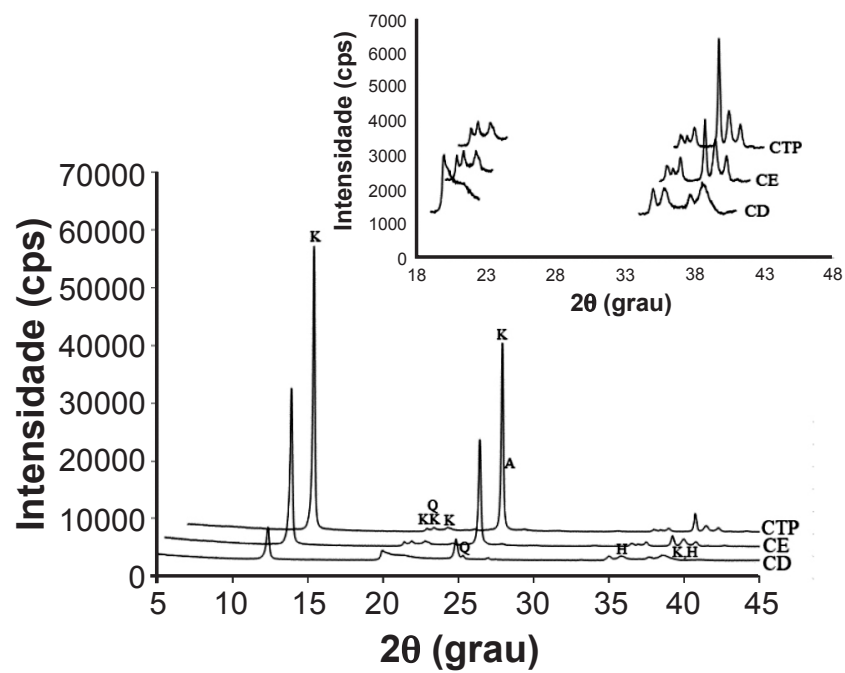

Figura 1: Difratograma de raios $\mathrm{X}$ dos caulins in natura $\mathrm{CD}, \mathrm{CTP}$ e CE Caulinita (K), Anatásio (A), Hematita (H) e Quartzo (Q).

[Figure 1: XRD patterns of kaolin in nature CD, CTP and CE. Kaolinite $(K)$, anatase $(A)$, hematite $(H)$ and quartz $(Q)$.]

desordem estrutural dos caulins, tal característica pode ser feita tomando-se como base um triplete formado pelas reflexões contidas entre 4,45 e $3,73 \AA$ ( 19,9 a $\left.23,8^{\circ} 2 \theta\right)$ e outros dois entre 35 e $40^{\circ}$ (2Ө) [20], na qual uma caulinita com alto grau de ordem ao longo do eixo $b$ apresenta tais tripletes com picos bem desenvolvidos [18]. Para as amostras CTP e CE nota-se um alto grau de ordem, uma vez que mostram picos bem agudos e de alta intensidade nestas regiões. Já para o caulim CD isso não é observado, mostrando que o mesmo possui baixo grau de ordem estrutural. Estas modificações podem ocorrer pela substituição parcial do Al pelo Fe na folha octaédrica da cauliníta [21,22].

Análise química por fluorescência de raios X: A Tabela I mostra os resultados químicos para os caulins $\mathrm{CD}, \mathrm{CTP}$ e CE. Os percentuais dos óxidos de $\mathrm{Si} \mathrm{e} \mathrm{Al,} \mathrm{bem} \mathrm{como} \mathrm{perda} \mathrm{ao}$ fogo (PF) estão próximos ao valor teórico. Os dois primeiros óxidos apresentam alta concentração, 82\% em conjunto, característica favorável para utilização como matéria-prima

Tabela I - Análise química por FRX dos caulins CD, CTP e CE.

[Table I - XRF analysis of CD, CTP and CE kaolins.]

\begin{tabular}{|c|c|c|c|c|}
\hline Óxidos & $\mathrm{CD}(\%)$ & СТP $(\%)$ & $\mathrm{CE}(\%)$ & Caulinita teórica (\%) \\
\hline $\mathrm{SiO}_{2}$ & 43,92 & 46,714 & 47,08 & 46,3 \\
\hline $\mathrm{Al}_{2} \mathrm{O}_{3}$ & 37,7 & 37,995 & 37,32 & 39,8 \\
\hline $\mathrm{Fe}_{2} \mathrm{O}_{3}$ & $1,63^{*}$ & 0,53 & 0,53 & - \\
\hline $\mathrm{Na}_{2} \mathrm{O}$ & $<0,01$ & 0,227 & 0,19 & - \\
\hline $\mathrm{TiO}_{2}$ & 2,05 & 0,273 & 0,42 & - \\
\hline $\mathrm{ZrO}_{2}$ & 0,15 & 0,013 & 0 & - \\
\hline $\mathrm{PF}$ & 14,3 & 14,04 & 14,36 & 13,9 \\
\hline Total & 99,76 & 99,79 & 99,9 & - \\
\hline
\end{tabular}

*obtido a partir de análise espectrofotométrica. 
Tabela II - Dados da extração de ferro dos caulins CD, CD600 e CD700.

[Table II - Iron removal data of CD, CD600 and CD700 kaolins.]

\begin{tabular}{|c|c|c|c|c|c|c|c|c|c|}
\hline \multirow{2}{*}{$\frac{\text { Lixiviação }}{1^{\mathrm{a}}}$} & \multicolumn{3}{|c|}{$\mathrm{CD}\left(\% \mathrm{Fe}_{2} \mathrm{O}_{3}\right)$} & \multicolumn{3}{|c|}{$\mathrm{CD} 600\left(\% \mathrm{Fe}_{2} \mathrm{O}_{3}\right)$} & \multicolumn{3}{|c|}{$\mathrm{CD} 700\left(\% \mathrm{Fe}_{2} \mathrm{O}_{3}\right)$} \\
\hline & 1,4665 & 1,4835 & 1,4755 & 1,3921 & 1,3268 & 1,2678 & 1,0921 & 1,0905 & 1,1143 \\
\hline $2^{\mathrm{a}}$ & 0,1119 & 0,1339 & 0,0937 & 0,1573 & 0,1654 & 0,2251 & 0,2887 & 0,2799 & 0,2792 \\
\hline $3^{\mathrm{a}}$ & 0,0168 & 0,0161 & 0,0117 & 0,0202 & 0,0230 & 0,0296 & 0,0604 & 0,0563 & 0,0579 \\
\hline $4^{\mathrm{a}}$ & 0,0141 & 0,0056 & 0,0067 & 0,0096 & 0,0079 & 0,0087 & 0,0197 & 0,0205 & 0,0170 \\
\hline Total & 1,6095 & 1,6394 & 1,5877 & 1,5791 & 1,5231 & 1,5311 & 1,4610 & 1,4472 & 1,4684 \\
\hline \multicolumn{10}{|c|}{ Extração em relação ao percentual de $\mathrm{Fe}_{2} \mathrm{O}_{3}$ inicial * } \\
\hline Base seca & 84,38 & 85,95 & 83,24 & 83,45 & 80,50 & 80,92 & 77,13 & 76,40 & 77,53 \\
\hline
\end{tabular}

Tabela III - Valores estatísticos do teste de Tukey.

[Table III - Statistical values of the Tukey test.]

\begin{tabular}{|c|c|c|c|c|c|}
\hline & Níveis & Centro & Lim.Inferior & Lim.Superior & P-Valor \\
\hline \multirow{3}{*}{ 己ి } & $2-1$ & 0,00745 & $-1,40695$ & 1,42185 & 0,99988 \\
\hline & $3-1$ & $-0,00542$ & $-1,41983$ & 1,40898 & 0,99993 \\
\hline & $3-2$ & $-0,01287$ & $-1,42728$ & 1,40153 & 0,99964 \\
\hline \multirow{3}{*}{ 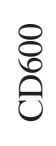 } & $2-1$ & $-0,01400$ & $-1,26625$ & 1,23825 & 0,99946 \\
\hline & $3-1$ & $-0,01200$ & $-1,26424$ & 1,24025 & 0,99961 \\
\hline & $3-2$ & 0,00200 & $-1,25024$ & 1,25425 & 0,99999 \\
\hline \multirow{3}{*}{$\frac{8}{8}$} & $2-1$ & $-0,00346$ & $-0,99677$ & 0,98986 & 0,99995 \\
\hline & $3-1$ & 0,00185 & $-0,99146$ & 0,99516 & 0,99999 \\
\hline & $3-2$ & 0,00531 & $-0,98800$ & 0,99862 & 0,99988 \\
\hline
\end{tabular}

zeolítica, uma vez que estes são constituintes principais destes compostos zeolíticos [14]. Os valores encontrados para o $\mathrm{Fe}_{2} \mathrm{O}_{3}$ e $\mathrm{TiO}_{2}$ no $\mathrm{CD}$, diferem substancialmente dos caulins CTP e CE, provocados principalmente pela maior presença de minerais acessórios como hematita $\left(\mathrm{Fe}_{2} \mathrm{O}_{3}\right)$ e anatásio $\left(\mathrm{TiO}_{2}\right)$, fato relacionado ao não beneficiamento deste material frente aos outros dois. O percentual de ferro no CD também pode estar relacionado a possíveis substituições isomórficas de $\mathrm{Al}^{+3}$ por $\mathrm{Fe}^{+3}$ no horizonte mineralógico deste caulim $[19,23]$.

Extração de ferro: Os dados da extração de ferro (em base seca) dos caulins CD in natura, calcinados a $600{ }^{\circ} \mathrm{C}$ (CD600) e $700{ }^{\circ} \mathrm{C}$ (CD700) estão dispostos na Tabela II. A maior parte do ferro foi removido na primeira lixiviação, aproximadamente $70 \%$ nas formas in natura e calcinada a $600{ }^{\circ} \mathrm{C}$ e $60 \%$ a $700{ }^{\circ} \mathrm{C}$, o percentual remanescente foi posteriormente removido nas lixiviações subsequentes. $\mathrm{O}$ tratamento térmico até $500{ }^{\circ} \mathrm{C}$ em um caulim contendo ferro promove uma difusão parcial deste metal da estrutura do argilomineral para a sua superfície, seguido de uma oxidação e formação de compostos férricos coloridos [24, 25]. Em calcinações realizadas entre $500^{\circ} \mathrm{C}$ a $1350{ }^{\circ} \mathrm{C}$, o ferro vai para a estrutura da fase formada e assim, gera uma diminuição na coloração vermelha da amostra [24, 25]. As extrações realizadas com os materiais termicamente tratados mostraram um menor percentual quando comparados com a amostra in natura, possivelmente relacionadas a difusão do ferro para a estrutura do caulim, uma vez que foram utilizadas temperaturas de 600 e $700^{\circ} \mathrm{C}$ na calcinação, e com isso um menor teor de ferro foi exposto a solução lixiviante. Da mesma forma, podemos notar uma maior extração de ferro em $600{ }^{\circ} \mathrm{C}$ em comparação com $700{ }^{\circ} \mathrm{C}$, novamente podendo estar relacionada ao processo difusivo do ferro em relação a temperatura de calcinação.

O resultado do teste de Tukey apresentado na Tabela III descreve uma igualdade entre os três ensaios, ou réplicas (níveis) de extração de ferro nos caulins CD, CD600 e CD700. Uma vez que, a um nível de significância $(\alpha)$ de 0,05 os comparativos dos três níveis de cada caulim apresentam uma probabilidade de significância (P-Valor) maior que este valor.

Análises termogravimétrica e térmica diferencial: $\mathrm{Na}$ curva de análise térmica diferencial (Fig. 2) do CE próximo a $300{ }^{\circ} \mathrm{C}$ nota-se um pequeno pico exotérmico, provavelmente relacionado à combustão do dispersante (poliacrilato) adicionado a este material [26]. Também observa-se um pico endotérmico referente à reação termal de desidroxilação da caulinita para a formação de metacaulinita iniciando em 476 ${ }^{\circ} \mathrm{C}$ e terminando em $663{ }^{\circ} \mathrm{C}$ para o CTP e $704{ }^{\circ} \mathrm{C}$ para o CE. Essa diferença na temperatura final poder estar relacionada à presença de booklets no CTP (Fig. 4), no qual uma maior temperatura para o final da reação termal é necessária, a fim de compensar a diminuição da área exposta à transferência de calor [27]. Outra hipótese para esta diferença pode ser 


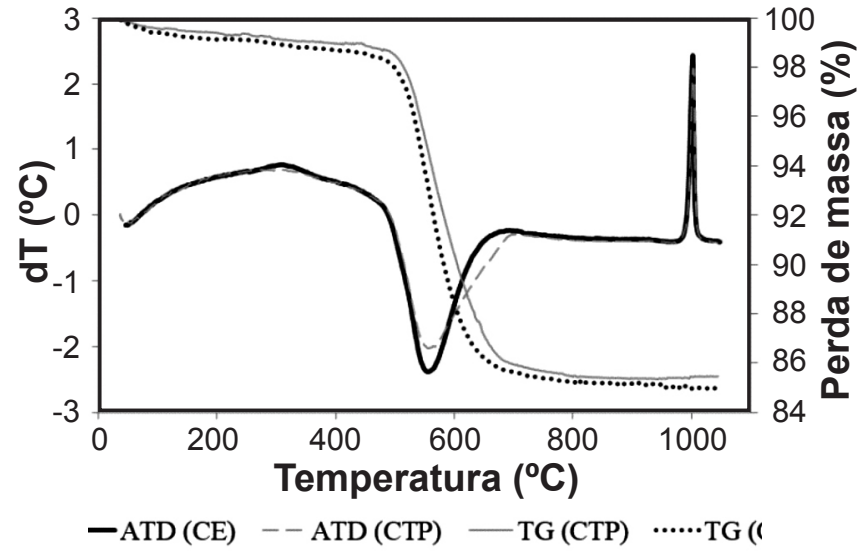

Figura 2: Curvas de análises termogravimétrica e térmica diferencial dos caulins tube press e enchimento.

[Figure 2: TGA and DTA curves of tube press and coating kaolins.]

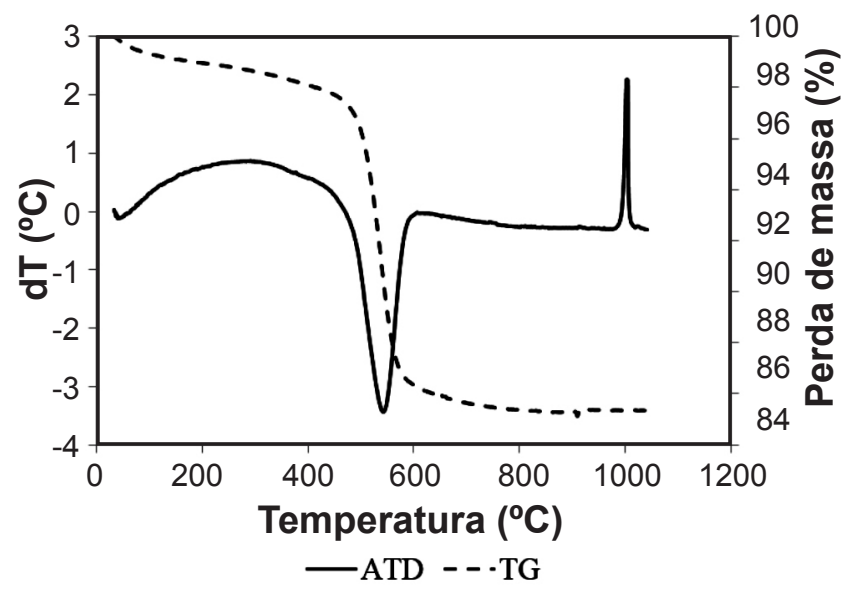

Figura 3: Curvas de análises termogravimétrica e térmica diferencial do caulim duro.

[Figure 3: TGA and DTA curves of hard kaolin.]

a fragilização das partículas do caulim ao longo do seu beneficiamento, pois como já apresentado, o CE é o produto final, assim este pode ter sofrido tal fragilização gerando desta forma, uma diminuição na sua temperatura final de desidroxilação em comparação ao CTP. Um pico exotérmico na região entre $970{ }^{\circ} \mathrm{C}$ e $1029{ }^{\circ} \mathrm{C}$ está relacionado com a nucleação da mulita a partir da recristalização da metacaulinita [27, 28]. Na análise termogravimétrica observa-se uma perda de massa em $\sim 14,4 \%$ para o CTP e CE, próximo ao valor teórico da caulinita de $13,96 \%$.

Na Fig. 3 tem-se os resultados da análise TG/DTA do CD. Há um perfil típico de transformação térmica da caulinita. O pico endotérmico característico da desidroxilação está na região entre $419{ }^{\circ} \mathrm{C}$ e $612{ }^{\circ} \mathrm{C}$ e o pico exotérmico referente à recristalização da metacaulinita em mulita entre $981{ }^{\circ} \mathrm{C}$ e $1026^{\circ} \mathrm{C}$. A diferença na amplitude do pico endotérmico encontrado neste caulim, com relação aos dois primeiros, pode estar relacionada à diferença no grau de ordem cristalina entre estes, pois uma caulinita bem cristalizada apresenta um alargamento neste pico endotérmico e o oposto em caulinitas mal cristalizadas $[27,28]$. Assim como para o
CTP e CE o CD, também apresenta em sua análise térmica um valor bem próximo à perda de massa teórica da caulinita, em torno de $14,60 \%$.

Análise morfológica por microscopia eletrônica de varredura: Na imagem do CTP mostrada na Fig. 4 observase uma massa heterogênea com aglomerados de partículas sem forma definida e porções pontuais com estruturas vermiculares (booklets) ambas com diâmetros que variam de 2 até $10 \mu \mathrm{m}$. A micrografia do CE (Fig. 5) não mostra estas estruturas, mas uma ligeira diminuição das porções de aglomerados; tal mudança está ligada ao seu beneficiamento, que passa por um processo de delaminação para a remoção dos booklets a fim de melhorar a sua utilização como cobertura e/ou carga de papel [26]. A imagem do CD mostra (Fig. 6) aglomerados de diferentes tamanhos, caracterizando-o como um material heterogêneo. O perfil hexagonal característico das particulas de caulinita é menos nítido em caulins com desordem estrutural, como é o caso do caulim CD; nestes, as

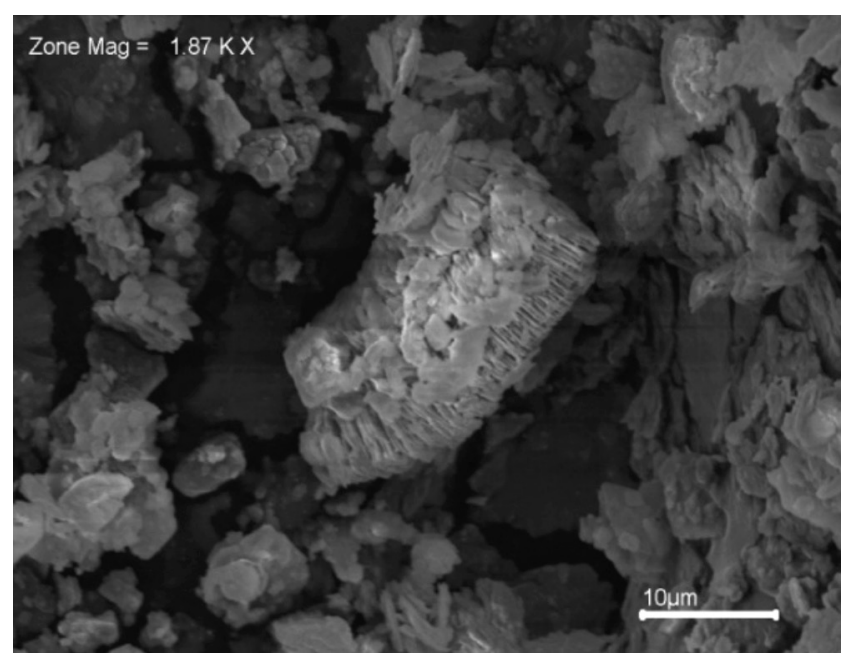

Figura 4: Micrografia obtida em microscópio eletrônico de varredura do CTP in natura.

[Figure 4: SEM micrograph of CTP in natura.]

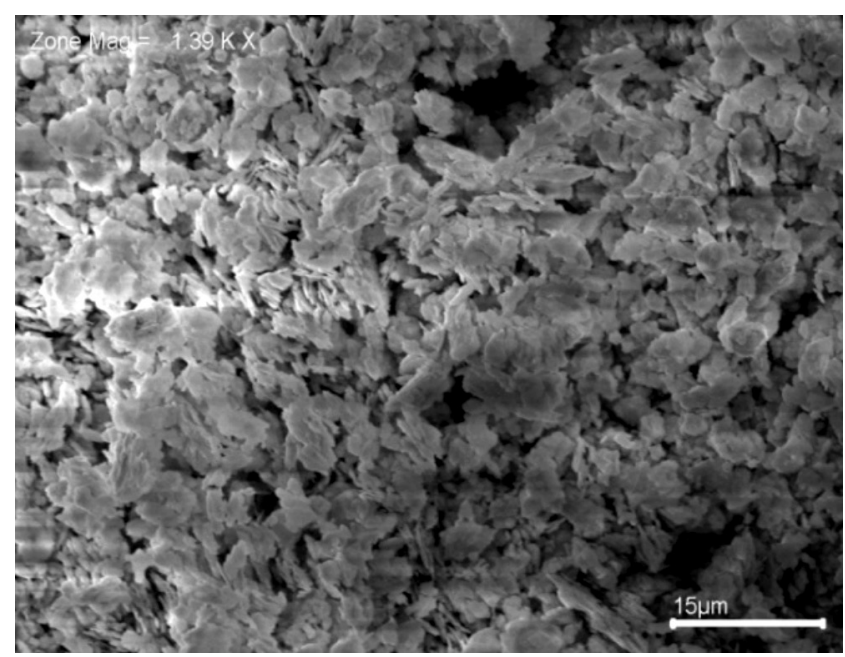

Figura 5: Micrografia obtida em microscópio eletrônico de varredura do caulim $\mathrm{CE}$.

[Figure 5: SEM micrograph of CE kaolin.] 


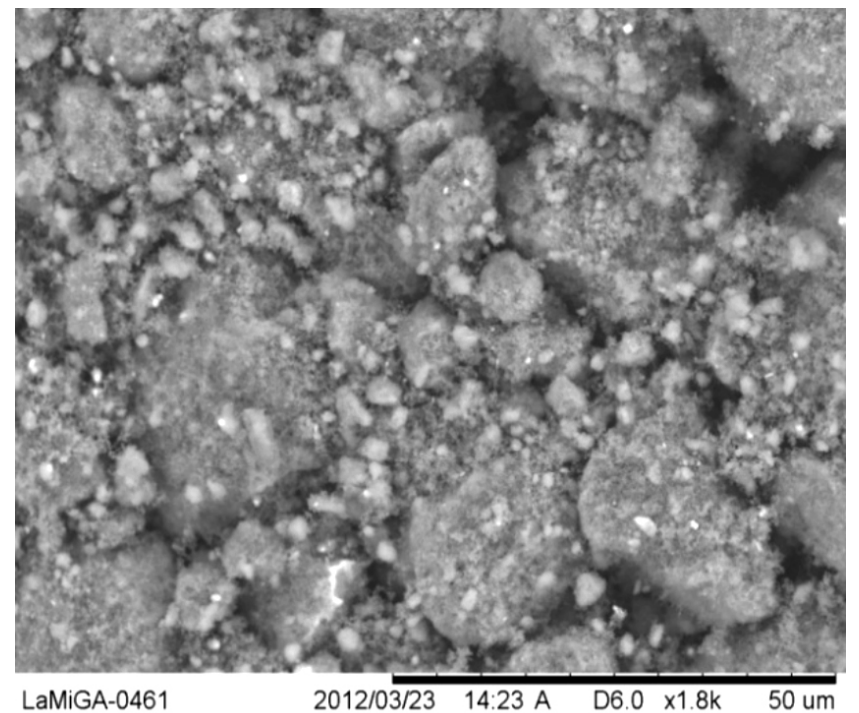

Figura 6: Micrografia obtida em microscópio eletrônico de varredura do caulim $\mathrm{CD}$.

[Figure 6: SEM micrograph of CD kaolin.]

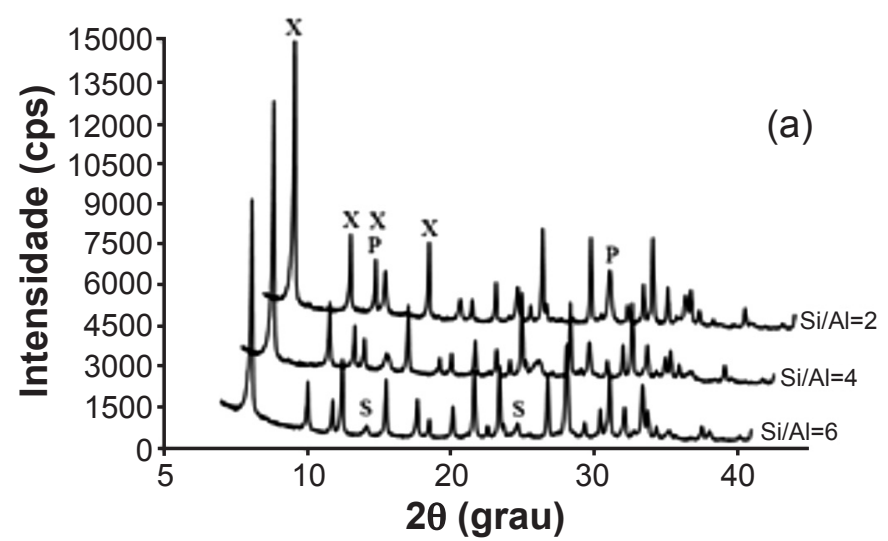

partículas apresentam granulometria muito baixa, podendo formar densos aglomerados que não se dispersam facilmente em água e apresentam uma grande resistência mecânica [28, 29].

Ensaios de síntese da faujasita: Nas Figs. 7 a 10 são apresentados os difratogramas de raios $\mathrm{X}$ das zeolitas a partir dos caulins calcinados CTP, CE e CD nas condições reacionais de $110{ }^{\circ} \mathrm{C}, 13 \mathrm{~h}$ e relações de $\mathrm{Si} / \mathrm{Al}$ de 2,4 e 6 . Verifica-se a formação de zeólita do tipo faujasita (X e Y) em todas as condições reacionais adotadas, assim como a presença de outras fases com menor intensidade de pico como: zeólita A, P, sodalita e chabazita. Para que houvesse uma distinção mais exata entre os tipos faujasita, foi utilizado em conjunto a análise térmica. No difratograma de raios $\mathrm{X}$ do caulim CTP (Fig. 7) nota-se que o aumento na relação de $\mathrm{Si} / \mathrm{Al}$ no meio reacional promoveu uma diminuição na intensidade dos picos da zeólita $\mathrm{X}$, possivelmente relacionado à redução da sua cristalinidade, sendo este evento também reportado $[8,30]$. Este incremento na concentração de silício na solução gera um excesso que pode não ser incorporado na

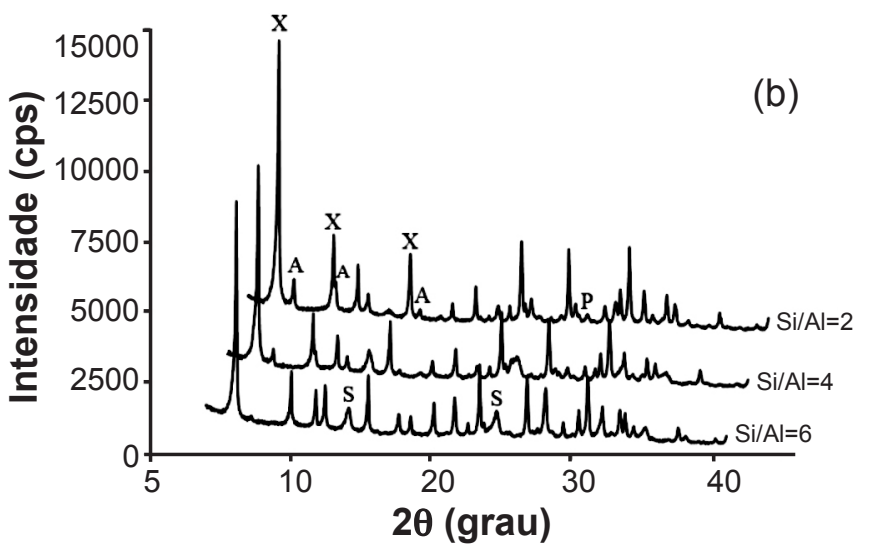

Figura 7: Difratogramas de raios $\mathrm{X}$ dos produtos zeolíticos a partir do a) caulim CTP calcinado a $600{ }^{\circ} \mathrm{C}$ e b) $700{ }^{\circ} \mathrm{C}$ com relações de $\mathrm{Si} / \mathrm{Al}$ igual a 2, 4 e 6. Zeólita X (X), zeólita A (A), sodalita (S), zeólita P (P).

[Figure 7: XRD patterns of zeolite product from a) CTP kaolin calcined at $600{ }^{\circ} \mathrm{C}$ and b) $700{ }^{\circ} \mathrm{C}$ with ratios Si / Al equal 2, 4 and $6 . \mathrm{Zeolite}$ $X(X)$, zeolite $A(A)$, sodalite $(s)$, zeolite $P(P)$.]
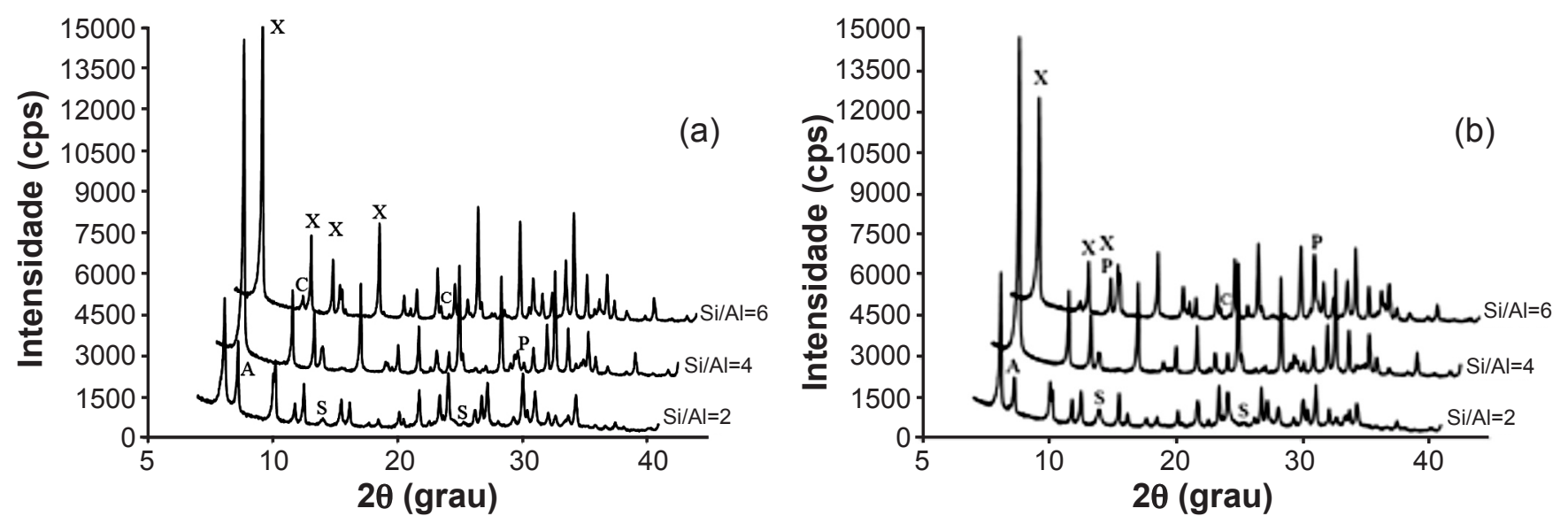

Figura 8: Difratogramas de raios $\mathrm{X}$ dos produtos zeolíticos a partir do a) caulim $\mathrm{CE}$ calcinado a $600{ }^{\circ} \mathrm{C}$ e b) $700{ }^{\circ} \mathrm{C}$ com relações de $\mathrm{Si} / \mathrm{Al}$ igual a 2, 4 e 6. Zeólita X (X), zeólita A (A), sodalita (S), zeólita P (P) e zeólita chabazita (C).

[Figure 8: XRD patterns of zeolite product from a) CE kaolin calcined at $600{ }^{\circ} \mathrm{C}$ and b) $700{ }^{\circ} \mathrm{C}$ with ratios Si / Al equal 2, 4 and $6 . \mathrm{Zeolite}$ $X(X)$, zeolite $A(A)$, sodalite $(s)$, zeolite $P(P)$ chabazite zeolite $(C)$. 

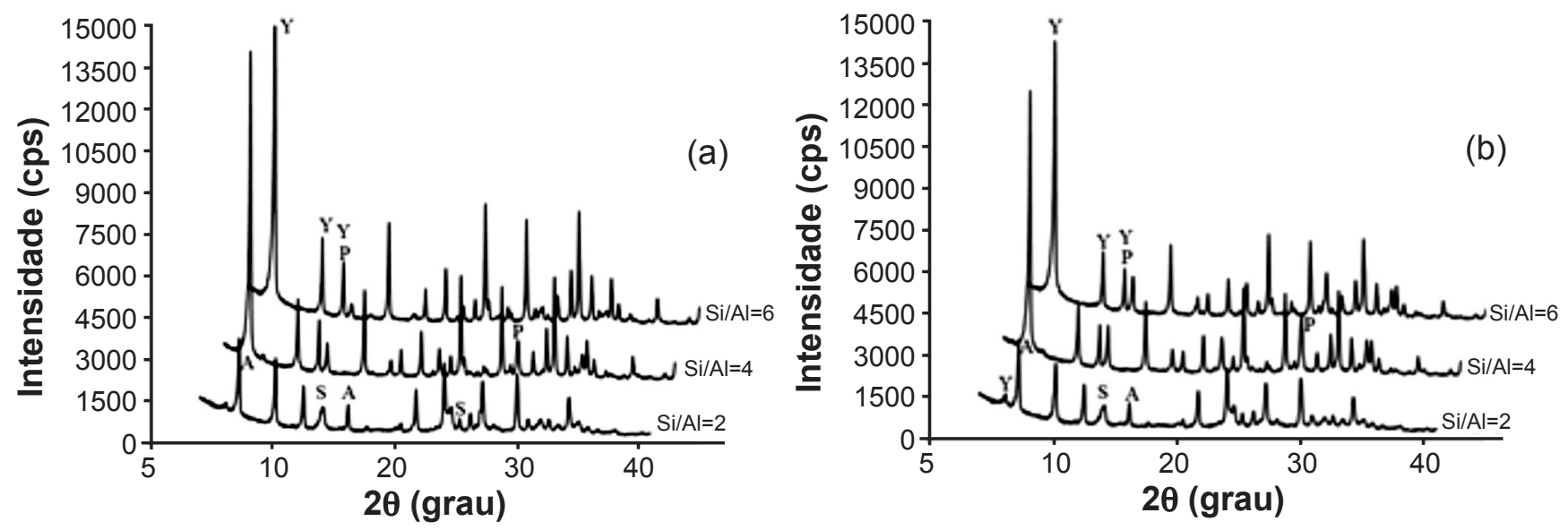

Figura 9: Difratogramas de raios $\mathrm{X}$ dos produtos zeolíticos a partir do a) caulim $\mathrm{CD}$ calcinado a $600{ }^{\circ} \mathrm{C}$ e b) $700{ }^{\circ} \mathrm{C}$ com relações de $\mathrm{Si} / \mathrm{Al}$ igual a 2, 4 e 6. Zeólita Y (Y), zeólita A (A), sodalita (S), zeólita P (P).

[Figure 9: XRD of zeolite product from a) CD kaolin calcined at $600{ }^{\circ} \mathrm{C}$ and b) $700{ }^{\circ} \mathrm{C}$ with ratios Si / Al equal 2, 4 and 6. Zeolite Y (Y), zeolite A (A), sodalite $(s)$, zeolite $P(P)$.
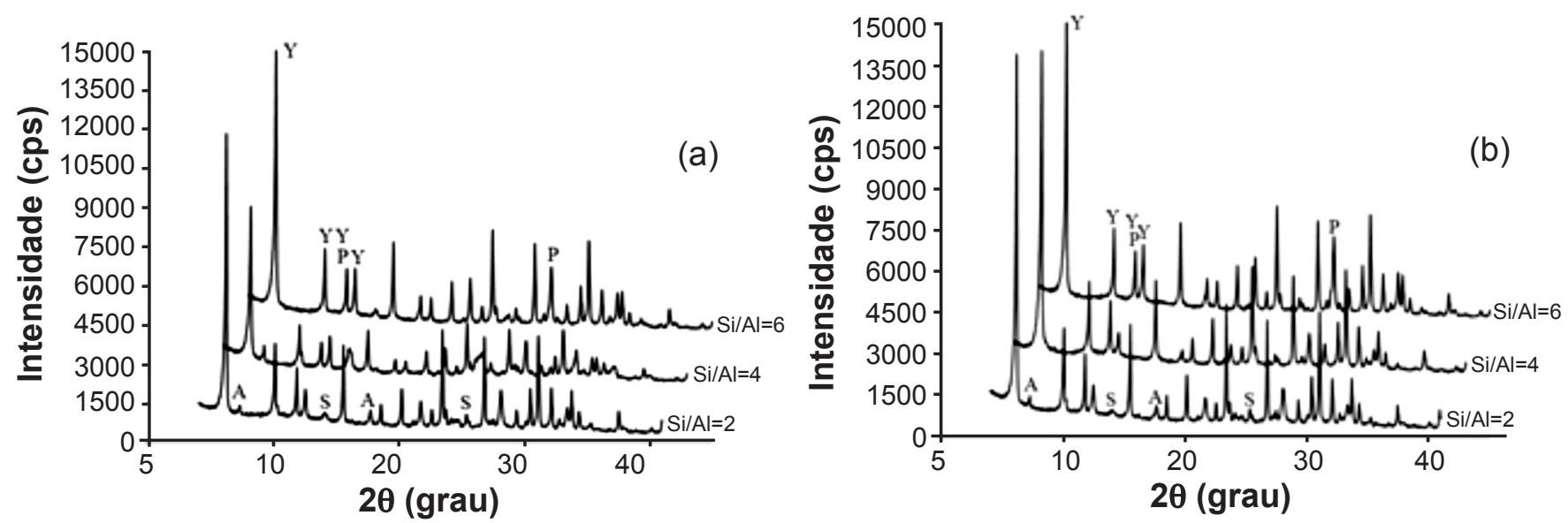

Figura 10: Difratogramas de raios $\mathrm{X}$ dos produtos zeolíticos a partir do a) caulim $\mathrm{CD}$ tratado (lixiviado), calcinado a $600{ }^{\circ} \mathrm{C}$ e b) $700{ }^{\circ} \mathrm{C}$ com relações de Si/Al igual a 2, 4 e 6. Zeólita Y (Y), zeólita A (A), sodalita (S), zeólita P (P).

[Figure 10: XRD patterns of zeolite product from a) kKaolin CD treated (leached), calcined at $600{ }^{\circ} \mathrm{C}$ and b) $700{ }^{\circ} \mathrm{C}$ with ratios $\mathrm{Si} / \mathrm{Al}$ equal 2, 4 and 6. Zeolite $Y(Y)$, zeolite $A(A)$, sodalite $(s)$, zeolite $P(P)$.

estrutura da zeólita, mas precipitado como silicato amorfo, que dilui os cristais desta zeólita causando um decréscimo na intensidade dos seus picos, além de favorecer a formação de outros tipos zeolíticos [31,32].

Para os caulins CE (Fig. 8) e CD (Fig. 9) não foi observado uma diminuição, mas um aumento na intensidade dos picos de suas zeólitas X e Y, respectivamente, com a elevação da razão de Si/Al. A química da síntese de zeólita é sujeita a perturbações causadas pela presença de impurezas no material de partida [33]. No caso do CE, este por apresentar um maior número de processos de beneficiamento que o CTP, possíveis adições de reagentes como defloculantes, dispersantes, branqueadores e outros, podem ter interferido no meio reacional. Da mesma forma, que as impurezas relacionadas ao ferro no material bruto $\mathrm{CD}$, podem ter causado a mesma perturbação no processo de síntese.

Para o caulim CD é possível verificar (Fig. 9), que apenas a relação de $\mathrm{Si} / \mathrm{Al}$ igual a 2 não formou zeólita $\mathrm{Y}$ como fase dominante. Foi mostrada a existência de uma relação específica entre o $\mathrm{Fe}, \mathrm{Al}$ e $\mathrm{Si}$ capaz de modificar a cristalinidade desta zeólita [34]. Dessa maneira, observase na Fig. 10 que após o tratamento do caulim CD para a remoção de ferro, houve uma total modificação quanto à intensidade dos picos da zeólita $\mathrm{Y}$, que passou a ser a fase principal. Porém, o percentual retirado não foi capaz de alterar significativamente a cristalinidade nas relações maiores de $\mathrm{Si} / \mathrm{Al}$.

Análises termogravimétrica e térmica diferencial: $\mathrm{Na}$ Fig. 11 são mostrados resultados de análise térmica de alguns produtos zeolíticos dos caulins CTP, CE e CD. Há uma continua perda de água superficial e água zeolítica na faixa de temperatura aproximadamente de 30 a $300{ }^{\circ} \mathrm{C}$, evidenciada pela presença do pico endotérmico na curva de análise térmica diferencial de todos os produtos. As zeólitas $\mathrm{X} \mathrm{e} \mathrm{Y}$ apresentam picos distintos nas regiões de alta temperatura da análise térmica [14]. A zeólita $\mathrm{X}$ tem como 

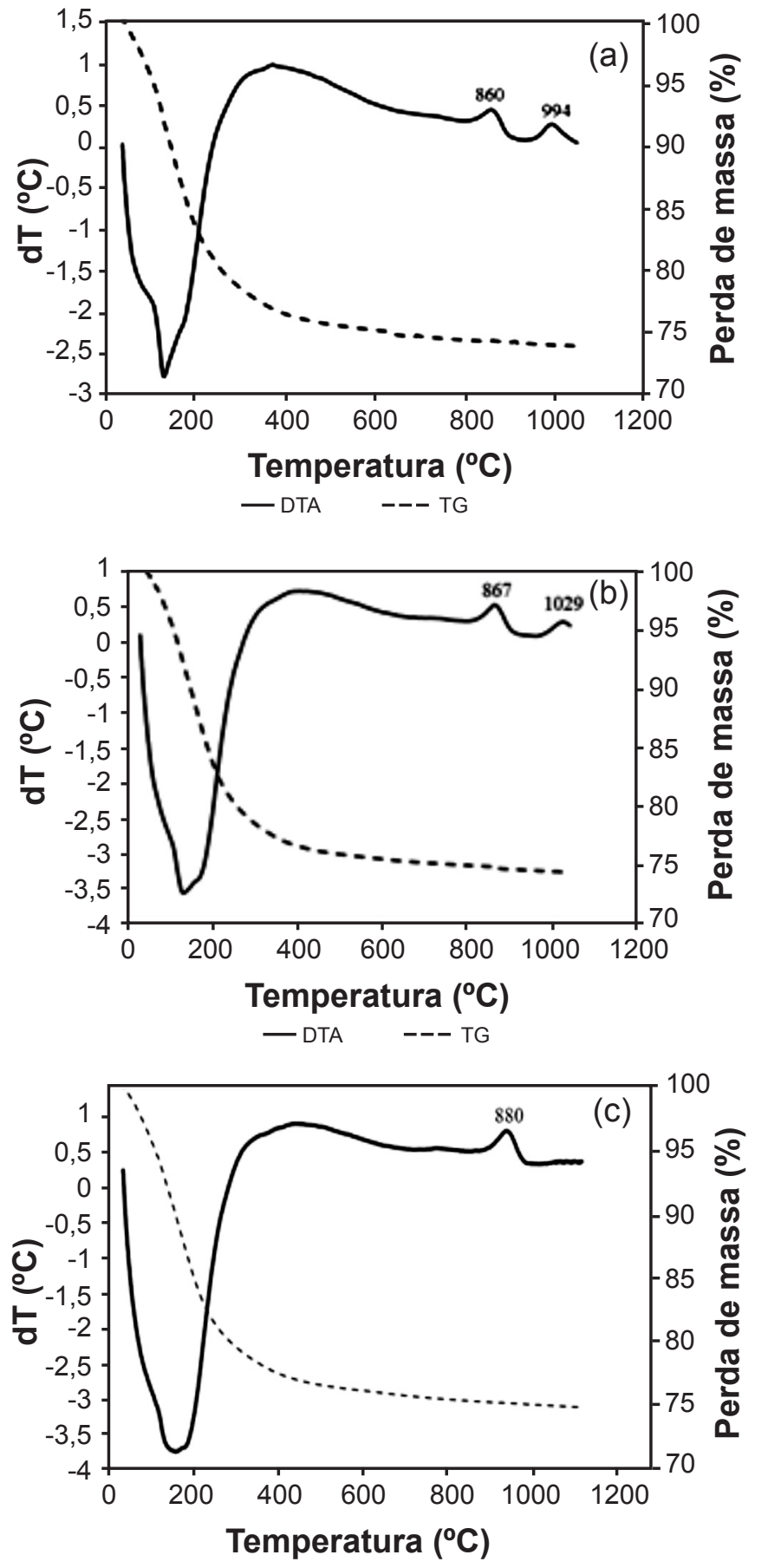

Figura 11: Curvas de análise térmica dos produtos: a) $\mathrm{CTP}\left(600{ }^{\circ} \mathrm{C}\right.$, $\mathrm{Si} / \mathrm{Al}$ igual a 2$), \mathrm{b}) \mathrm{CE}\left(600^{\circ} \mathrm{C}, \mathrm{Si} / \mathrm{Al}\right.$ igual a 4$)$ e c $) \mathrm{CD}\left(600^{\circ} \mathrm{C}, \mathrm{Si} /\right.$ $\mathrm{Al}$ igual a 2).

[Figure 11: Thermal analysis curves of the products: a) CTP (600 ${ }^{\circ} \mathrm{C}$, Si/Al equal 2), b) $C E\left(600^{\circ} \mathrm{C}\right.$, Si/Al equal 4) and c) $C D$ (600 ${ }^{\circ} \mathrm{C}$, Si/Al equal 2).]

característica dois picos nesta região, um próximo a $800{ }^{\circ} \mathrm{C}$ e outro a $940{ }^{\circ} \mathrm{C}$, referentes à decomposição e em seguida recristalização em uma outra fase mineralógica, enquanto que a zeólita $\mathrm{Y}$ apresenta um único pico próximo a $850{ }^{\circ} \mathrm{C}$ decorrente do colapso estrutural para a formação de um material amorfo.
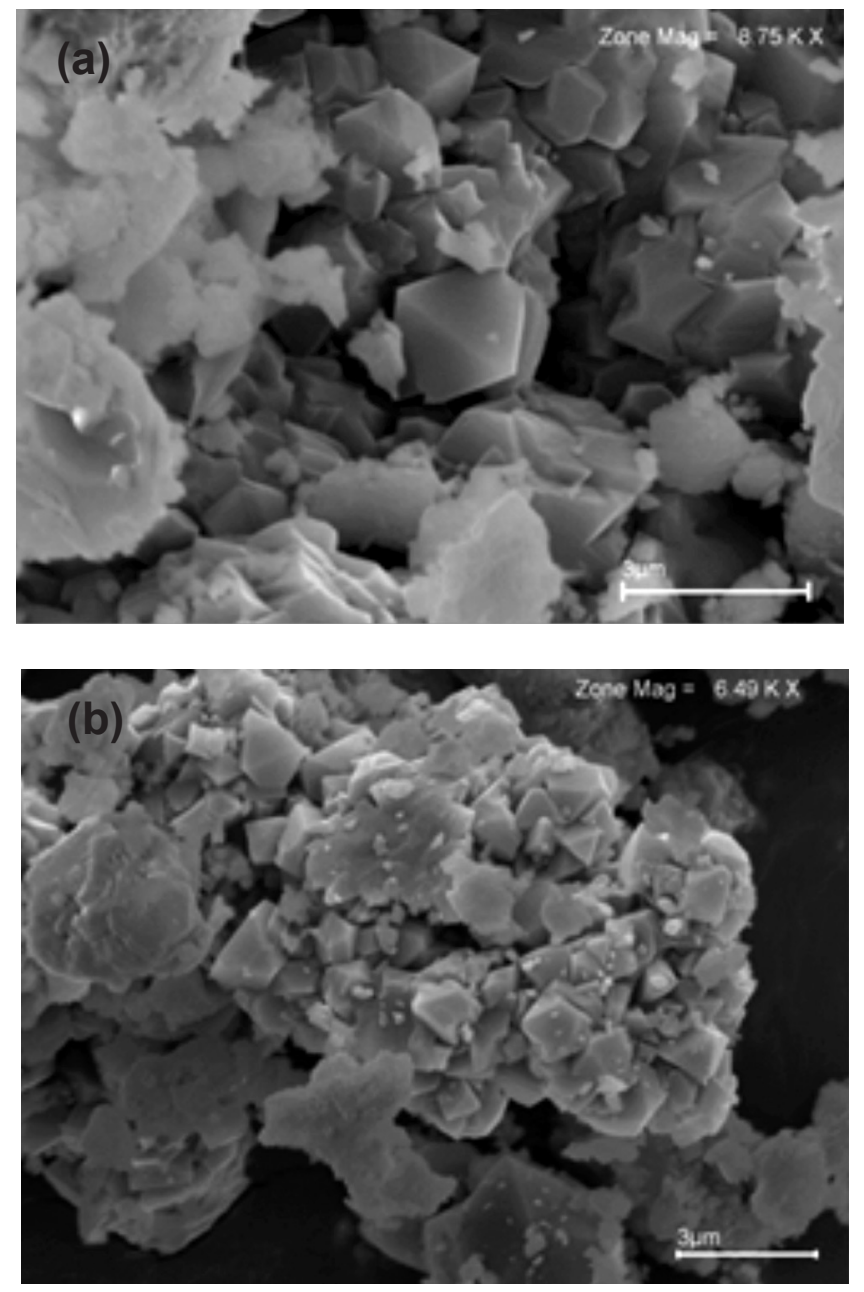

Figura 12: Micrografia obtida em microscópio eletrônico de varredura dos produtos de síntese a) $\mathrm{CE}\left(700{ }^{\circ} \mathrm{C}, \mathrm{Si} / \mathrm{Al}\right.$ igual a 4) e b) $\mathrm{CD}\left(600{ }^{\circ} \mathrm{C}, \mathrm{Si} / \mathrm{Al}\right.$ igual a 6$)$.

[Figure 12: SEM micrographs of synthesis products a) CE (700 ${ }^{\circ}$ $\mathrm{C}$, Si / Al equal 4) and b) $C D\left(600^{\circ} \mathrm{C}\right.$, Si / Al equal 6).]

Vale ressaltar que possíveis variações nas posições dos picos de cada uma destas zeólitas podem ocorrer, uma vez que foi mostrado que a análise térmica diferencial é influenciada por tamanho de partícula, cristalinidade, taxa de aquecimento e atmosfera [14,27].

A Fig. 11 mostra uma perda de massa de $\sim 25 \%$ para os produtos zeolíticos a partir dos caulins CTP e CE. Este valor está bem próximo ao reportado para as zeólitas X e Y [14].

Análise morfológica por microscopia eletrônica de varredura: As análises de microscopia eletrônica de varredura de alguns produtos de síntese são mostradas na Fig. 12. Podem ser observados cristais de zeólita faujasita, com morfologia octaédrica e feições geminadas (intercrescidos). Estas morfologias também foram observadas na síntese de faujasita a partir de caulim da mesma região geológica do caulim utilizado no presente trabalho [35].

\section{CONCLUSÕES}

Os caulins de enchimento (CE), tube press (CTP) e duro 
(CD) estudados neste trabalho mostram-se boas matériasprimas para a síntese de zeólita faujasita, uma vez que em todas as condições reacionais foi possível a obtenção deste material zeolítico. Os produtos obtidos com os caulins beneficiados não mostraram diferenças significativas entre si. Estes, em comparação com o material zeolítico obtido com o caulim $\mathrm{CD}$, também não mostraram diferença apreciável com relação às maiores razões de $\mathrm{Si} / \mathrm{Al}$ (4 e 6). Porém, para a relação igual a 2 há uma notória diferença relacionada à formação da zeólita faujasita, nos caulins beneficiados houve um domínio mineralógico desta fase, em quanto que no caulim duro a formação não foi expressiva. Para a modificação deste cenário houve a necessidade de remover o ferro presente neste caulim. A metodologia utilizada para a remoção do ferro presente no caulim CD mostrou-se bastante promissora, removendo em média $80 \%$. Porém, observa-se um pequeno incremento nesta remoção, quando aplicado no caulim in natura frente ao tratado termicamente. $\mathrm{O}$ beneficiamento do caulim na indústria do papel também mostrou-se influente quanto à formação da zeólita faujasita, uma vez que os caulins CTP e CE mostraram comportamentos inversos com a variação de $\mathrm{Si} / \mathrm{Al}$ no meio reacional, refletindo na intensidade dos picos desta zeólita. O conteúdo de ferro (1,63\% base úmida, $1,91 \%$ base seca) no caulim CD mostrou-se prejudicial somente nas sínteses com relação de Si/Al igual 2. Nas outras relações pode ter contribuído para o aumento da cristalinidade da zeólita faujasita formada.

\section{AGRADECIMENTOS}

Ao Conselho Nacional de Desenvolvimento Científico e Tecnológico (CNPq) pela bolsa de doutorado do primeiro autor. Aos Laboratórios de Difração e Fluorescência de raios $\mathrm{X}$, Análise Térmica Diferencial e Análise Termogravimétrica, Microscopia Eletrônica de Varredura e Análises Químicas do Instituto de Geociênciais da Universidade Federal do Pará, pelas análises.

\section{REFERÊNCIAS}

[1] http://www.mme.gov.br/sgm/galerias/arquivos/plano duo decenal/a mineracao brasileira/P28 RT39 Perfil do Caulim.pdf, acessada em outubro (2012).

[2] E. Saldanha, "Síntese e caracterização da analcima a partir de rejeito de caulim e aplicação como adsorvente", Diss. Mestrado, Universidade Federal do Pará, PA (2007)

[3] A. A. B. Maia, E. Saldanha, R. S. Angélica, C. A. Souza, R. F. Neves, Cerâmica 53 (2007) 319.

[4] A. A. B. Maia, E. Saldanha, R. S. Angélica, C. A. Souza, R. F. Neves, Cerâmica 54 (2008) 345.

[5] A. A. B. Maia, R. S. Angélica, R. F. Neves, Clay Miner. 46 (2011) 127.

[6] C. G. Moraes, E. C. Rodrigues, R. S. Angélica, E. N. Macêdo, R. F. Neves, Cerâmica 59 (2014) 563.

[7] S. P. A. Paz, R. S. Angélica, R. F. Neves, Quim. Nova 33 (2010) 579.

[8] E. A. Hildebrando, "Síntese de zeólita do tipo faujasita utilizando rejeito de caulim da Amazônia como fonte de silício e alumínio: Aplicação como adsorvente", Tese Dr.. Universidade de S. Paulo, S. Paulo, SP (2012).

[9] L. F. Sena, "Adsorção de Pb por Caulinita Tratada com Ácidos Acético e Cítrico", Diss. Mestrado, Universidade Federal do Pará, PA (2005).

[10] S. M. P. Flores, "Aproveitamento do rejeito de caulim na produção de alumina para cerâmica e sílica de baixa granulometria", Tese Dr., Universidade Federal do Pará, PA (2000).

[11] M. C. Martelli, “Transformações térmicas e propriedades cerâmicas de resíduos de caulins das regiões do Rio Capim e do Rio Jarí - “, Tese Dr., Universidade Federal do Pará, PA (2006).

[12] M. S. Barata, D. C. C. Dal Molin, Ambiente Construído 2 (2002) 69.

[13] M. S. Barata, "Aproveitamento dos resíduos cauliníticos das indústrias de beneficimento de caulim da região amazônica como matéria-prima para a fabricação de um material de construção (pozolanas)", Tese Dr., Universidade Federal do Pará, PA (2007).

[14] D. W. Breck, Zeolite Molecular Sieves, Wiley \& Sons, New York, EUA (1974).

[15] A. S. Araujo, "Influência de terras raras nas propriedades e atividade catalítica da zeólita Y", Tese Dr., Universidade de S. Paulo, SP (1992).

[16] D. N. Stamires, Clays, Clay Miner. 21 (1973) 379.

[17] G. P. Mehra, M. L. Jackson, Clays Clay Miner. 7 (1960) 317.

[18] A. Lucas, M. A. Uguina, I. Coviln, L. Rodriguez, Znd. Eng. Chem. Res. 31 (1992) 2134.

[19] B. S. Carneiro, R. S. Angélica, T. Scheller, E. A. S. Castro, R. F. Neves, Cerâmica 49 (2003) 237.

[20] J. Thorez, Identification of clay minerals: a handbook for teachers and students in clay minerals, eds. Dison: Lelotte (1976).

[21] B. Kotschoubey, A. L. S. Duarte, W. Truckenbrodt, Rev. Bras. Geoci. 29 (1999) 331.

[22] A. L Duarte, "Caulim do Morro do Felipe, baixo rio Jari, Estado do Amapá. Contexto geológico e gênese", Diss. Mestrado, Universidade Federal do Pará, PA (1996).

[23] P. S. R. Criscuolo, "Beneficiamento do caulim duro das bacias dos rios Capim e Jari através do processo de agregação seletiva", Diss. Mestrado, Universidade Federal de Minas Gerais, MG (2008).

[24] S. Chandrasekhar, Clay Miner. 31 (1996) 253.

[25] L. Stoch, Interceram. 6 (1987) 21.

[26] http://www.cetem.gov.br/publicacao/series srmi/srmi01.pdf, acessado em 08/2011.

[27] R. E. Grim, Clay Mineralogy. $2^{\text {nd }}$ ed., McGraw Hill: New York (1968).

[28] P. Souza Santos, Ciência e tecnologia de argilas, Vol.1. Edgard Blucher, S Paulo, SP (1989).

[29] D. J. L. Souza, “Caracterização geológica, mineralógica e física do caulim da mina da RCC - Rio Capim Caulim (PA)", Diss. Mestrado, Universidade Federal do Pará, PA (2000). 
[30] E. B. Drag, A. Miecznikowski, F. Abo-Lemon, M. Rutkowski, doi: 10.1016/S0167-2991(08)65279-9.

[31] L. Qiang, Z. Ying, C. Zhijun, G. Wei, C. Lishan, Pet. Sci. 7 (2010) 403.

[32] H. Lechert, P. Staelin, C. Kuntz, Zeolites 16 (1996) 149.
[33] H. Robson, Verified Syntheses of Zeolitic Materials, $2^{\text {nd }}$ ed., Elsevier Sci. Amsterdam, Holanda (2001).

[34] G. Zi, T. Dake, Z. Ruiming, Zeolites 8 (1988) 245.

[35] E. A. Hildebrando, R. S. Angélica, R. F. Neves, F. R. Valenzuela-Diaz, Cerâmica 58 (2012) 453.

(Rec. 27/01/2015, Rev. 18/04/2015, Ac. 19/04/2015) 